\title{
Cloning and expression of a novel lactococcal aggregation factor from Lactococcus lactis subsp. lactis BGKP1
}

Milan Kojic ${ }^{*}$ Branko Jovcic, Ivana Strahinic, Jelena Begovic, Jelena Lozo, Katarina Veljovic and Ljubisa Topisirovic

\begin{abstract}
Background: Aggregation may play a main role in the adhesion of bacteria to the gastrointestinal epithelium and their colonization ability, as well as in probiotic effects through co-aggregation with intestinal pathogens and their subsequent removal. The aggregation phenomenon in lactococci is directly associated with the sex factor and lactose plasmid co-integration event or duplication of the cell wall spanning (CWS) domain of PrtP proteinase.

Results: Lactococcus lactis subsp. lactis BGKP1 was isolated from artisanal semi-hard homemade cheese and selected due to its strong auto-aggregation phenotype. Subsequently, non-aggregating derivative (Agg') of BGKP1, designated as BGKP1-20, was isolated, too. Comparative analysis of cell surface proteins of BGKP1 and derivative BGKP1-20 revealed a protein of approximately $200 \mathrm{kDa}$ only in the parental strain BGKP1. The gene involved in aggregation (aggL) was mapped on plasmid PKP1 (16.2 kb), cloned and expressed in homologous and heterologous lactococci and enterococci. This novel lactococcal aggregation protein was shown to be sufficient for cell aggregation in all tested hosts. In addition to the aggL gene, six more ORFs involved in replication (repB and repX), restriction and modification ( $h s d S$ ), transposition (tnp) and possible interaction with mucin ( $m b p L$ ) were also located on plasmid pKP1.
\end{abstract}

Conclusion: AggL is a new protein belonging to the collagen-binding superfamily of proteins and is sufficient for cell aggregation in lactococci.

\section{Background}

The aggregation phenomenon in lactococci has been studied for more than thirty years. It was found to be directly associated with a sex factor and lactose plasmid co-integration event [1] or duplication of the cell wall spanning (CWS) domain of PrtP proteinase [2]. Lactose plasmid conjugation in Lactococcus lactis 712 and in the related strains C2 and ML3, frequently involves plasmid co-integration with a sex factor. Moreover, this phenomenon is often associated with a cell aggregation phenotype and high frequency transfer ability [3-5]. The lactococcal sex factor exists integrated in the chromosome [6], although it can be excised as a closed circular form and lost from the cell [1]. Deletion and overexpression experiments confirmed that CluA is the only

\footnotetext{
* Correspondence: mkojics@eunet.rs

Laboratory for Molecular Genetics of Industrial Microorganisms, Institute of Molecular Genetics and Genetic Engineering, University of Belgrade, Vojvode Stepe 444/a, P.O. Box 23, Belgrade 11010, Serbia
}

sex factor component responsible for aggregation in $L$. lactis. This $136 \mathrm{kDa}$ surface-bound protein, encoded by the chromosomally located sex factor of Lactococcus lactis subsp. cremoris MG1363, is associated with cell aggregation linked to high-frequency transfer [7]. Two domains of CluA involved in distinct functions were determined. The region from D153-I483 is important for promoting cell-to-cell binding (aggregation), whereas K784-K1056 Tra domain is involved in DNA transfer and responsible for high conjugation frequency [8]. Furthermore, the aggregation ability of L. lactis subsp. lactis BGMN1-5 and its cured derivative was dependent on the presence of the plasmid encoded extracellular proteinase, PrtP $[2,9]$. The PrtP proteinase of BGMN1-5 contains a duplication of the C-terminal cell wall spanning domain (CWS). Experiments in which hybrids of BGMN1-5 PrtP, containing one or more CWS domains were constructed, showed that only cells producing a fusion protein with two or more CWS domains

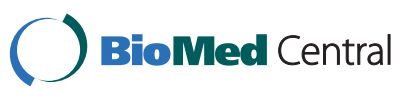

(c) 2011 Kojic et al; licensee BioMed Central Ltd. This is an Open Access article distributed under the terms of the Creative Commons Attribution License (http://creativecommons.org/licenses/by/2.0), which permits unrestricted use, distribution, and reproduction in any medium, provided the original work is properly cited. 
sedimented. Sedimentation resulted from specific interaction between CWS domains [2]. It is interesting that both, CluA protein and PrtP proteinase, have an LPXTG pentapeptide at the carboxy terminus, which is conserved among many cell surface proteins of Grampositive bacteria [10]. In Gram-positive bacteria, these proteins have a multitude of functions, which include binding to host cells and/or tissues or specific immune system components, protein processing, nutrient acquisition and interaction between bacteria during conjugation [11]. Many cell-surface proteins are involved in aggregation and adhesion processes, including the colonization of oral and commensal bacteria [12-14] and initiation of infection by pathogens [15-19]. Pathogenic Gram-positive bacteria express cell surface proteins that contribute to virulence [20]. The genes encoding the surface proteins derived from several Enterococcus faecalis plasmids, including pAD1, pPD1 and pCF10 have been sequenced [21-23] and over-expressed in different bacteria including Lactococcus lactis [24]. It was found that aggregation substance (AS), a surface protein of $E$. faecalis, might contribute to virulence [25].

L. lactis subsp. lactis BGKP1 was selected in our laboratory as a specific strain due to the expression of a unique auto-aggregation phenotype. In the present study, we isolated a non-aggregating derivative ( $\left.\mathrm{Agg}^{-}\right)$of BGKP1 and performed comparative analysis. We found that a cell surface protein of high molecular mass, around $200 \mathrm{kDa}$, is responsible for the aggregation. The gene encoding for aggregation protein (aggL) was mapped on plasmid pKP1 (16.2 kb). The gene was cloned, sequenced and expressed in homologous and heterologous lactococcal and enterococcal hosts, showing that AggL protein is responsible for cell aggregation in lactococci. Therefore, we propose AggL as a novel lactococcal aggregation factor.

\section{Results and Discussion}

Aggregation may play the main role in adhesion of bacteria to the gastrointestinal epithelium and their colonization ability, as well as in probiotic effects through coaggregation with intestinal pathogens and their subsequent removal.

\section{Isolation and comparative analyses of Lactococcus lactis subsp. lactis BGKP1 and its non-aggregating derivative BGKP1-20}

Considering the importance of aggregation, Lactococcus lactis subsp. lactis BGKP1 was selected during the characterization of microflora of artisanal white semi-hard homemade cheeses manufactured in the village of Rendara (altitude 700 m) on Kopaonik mountain, Serbia. Among 50 lactic acid bacteria (LAB), Lactococcus lactis subsp. lactis BGKP1 was chosen for further study due to its strong auto-aggregation phenotype $\left(\mathrm{Agg}^{+}\right)$.

BGKP1 is a lactose positive, bacteriocin and proteinase non-producing strain. The aggregation phenotype may be observed after vigorous mixing of a stationary phase culture, when snowflake-like aggregates become visible (Figure 1). The aggregates of BGKP1 cells differed in appearance from those of $L$. lactis subsp. cremoris MG1363 expressing CluA or L. lactis subsp. lactis BGMN1-5. Aggregates rapidly sedimented under resting conditions and more than 95\% of BGKP1 cells aggregated in the first minute, as observed by the decrease of cell suspension absorbance (data not shown). BGKP1 cell aggregates resemble those of Lactobacillus paracasei subsp. paracasei BGSJ2-8 [26]. The aggregation ability of BGKP1 was lost spontaneously after transfer of cells from $-80^{\circ} \mathrm{C}$ to $30^{\circ} \mathrm{C}$, with a frequency of $5 \%$ to $10 \%$, as previously shown for BGSJ2-8 [26]. The resulting nonaggregating derivative ( $\left.\mathrm{Agg}^{-}\right)$of BGKP1 was designated as BGKP1-20. $\mathrm{Agg}^{+}$cells formed smaller and prominent colonies, whereas Agg- derivatives showed flat colonies on agar plates. Mutations in genes encoding biofilmassociated proteins were also shown to result in transformation of colony morphology [27]. Since BGKP1 and BGKP1-20 were not able to form biofilms on plastic tissue culture plates, the aggregation phenomenon present in BGKP1 is most probably not linked to biofilm formation. Spontaneous high-frequency loss of the trait indicated a plasmid location of the gene(s) encoding the aggregation phenotype. Comparative analysis of the fitness of BGKP1 and BGKP1-20 in the exponential phase of growth showed differences in generation times between the strains. The doubling time for BGKP1 was $54.4 \mathrm{~min}$ (specific growth rate $=1.103 / \mathrm{h}$ ), while that for BGKP1-20 was $50.2 \mathrm{~min}$ (specific growth rate $=1.195$ / h). The presence of the aggregation phenotype resulted in a significantly prolonged doubling time for BGKP1 (approximately $8.5 \%$ ) when compared with that of BGKP1-20. Taking into consideration that bacteria maintain and procure gene coding for the aggregation factor in spite of the energy cost, we could hypothesize that this feature provides some benefit for the cell.

\section{Nature of molecules involved in aggregation}

The spontaneous loss of the capacity to aggregate in BGKP1 was tested under various conditions. Aggregation capacity was found to be reversibly lost after repeated washing of BGKP1 cells with bi-distilled water. Nevertheless, when washed BGKP1 cells that had lost the $\mathrm{Agg}^{+}$phenotype were re-suspended in the wash material, they re-gained the ability to aggregate. Obviously, a some molecule(s) with a role in aggregation were washed from the cell wall. However, aggregation 


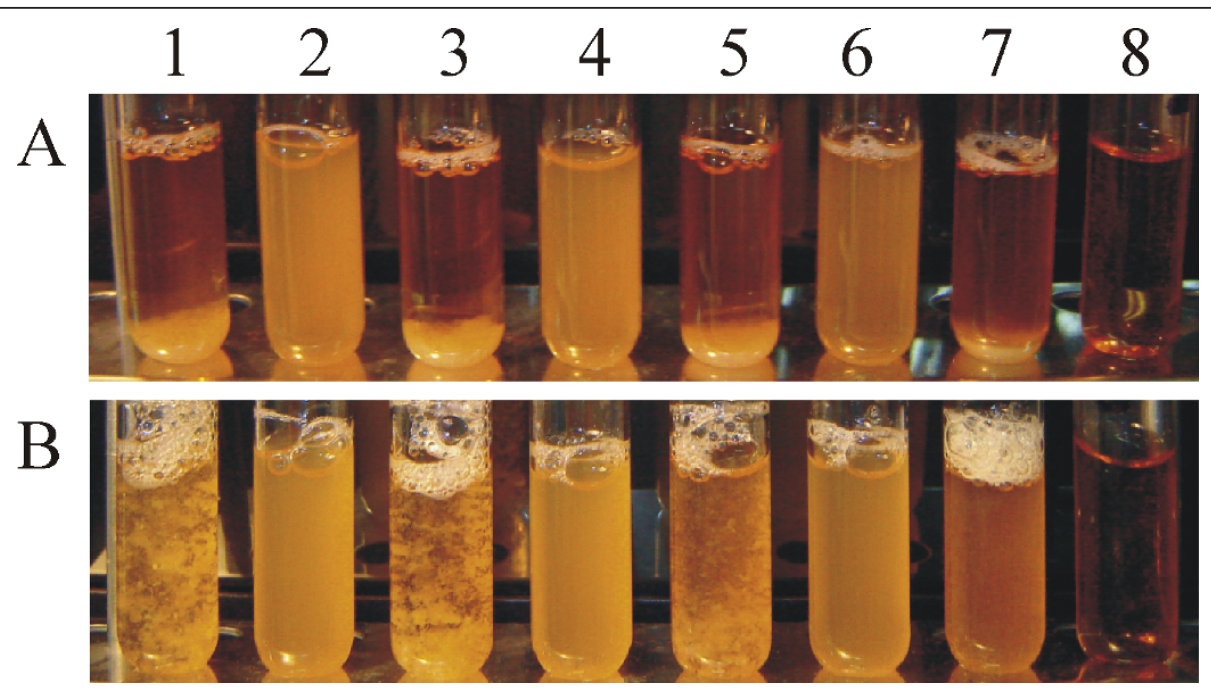

Figure 1 Aggregation ability of L. lactis subsp. lactis BGKP1, BGKP1-20 and transformants carrying pAZIL-KPPvSc1 in growth medium after overnight cultivation (A) and vigorous mixing (B). 1. L. lactis subsp. lactis BGKP1 (Agg ${ }^{+}$); 2. L. lactis subsp. lactis BGKP1-20 (Agg); 3. L. lactis subsp. lactis BGKP1-20/pAZIL-KPPVSc1; 4. L. lactis subsp. cremoris MG1363; 5. L. lactis subsp. cremoris MG1363/pAZIL-KPPVSc1; 6. L. lactis subsp. lactis BGMN1-596; 7. L. lactis subsp. lactis BGMN1-596/pAZIL-KPPvSc1; 8. GM17 medium.

was not observed when BGKP1-20 $\mathrm{Agg}^{-}$cells were resuspended in wash material from BGKP1 $\mathrm{Agg}^{+}$. To check the nature of molecules involved in the aggregation, BGKP1 $\mathrm{Agg}^{+}$cells were treated with proteinase $\mathrm{K}$ prior to washing by water. The wash material of proteinase K-treated cells did not restore the aggregation ability of BGKP1 $\mathrm{Agg}^{-}$washed cells. Results indicated that the aggregation factor is of proteinaceous nature. Since a protein is involved in aggregation, the influence of various $\mathrm{pH}$ levels and the concentration of five ions $\left(\mathrm{K}^{+}\right.$, $\mathrm{Na}^{+}, \mathrm{Ca}^{++}, \mathrm{Mg}^{++}$and $\mathrm{Fe}^{+++}$) on this phenomenon was examined. It was found that $\mathrm{pH}$ did not have as strong impact on the ability of BGKP1 to aggregate as cations did, especially iron. The presence of $1 \mathrm{mM} \mathrm{FeCl}_{3}$ promoted aggregation of BGKP1 washed cells.

Cell surface protein profiles of BGKP1 and the Agg derivative BGKP1-20 were compared in order to detect any differences between strains. As demonstrated for BGSJ2-8 [26], the SDS-PAGE pattern of cell surface proteins from BGKP1 and BGKP1-20 differed. Thus, $\mathrm{Agg}^{+}$ contained an additional $\approx 200 \mathrm{kDa}$ protein, which was absent from the BGKP1-20 $\mathrm{Agg}^{-}$derivative (Figure 2). This suggested that the aforementioned protein might be responsible for the aggregation. The protein detected and potentially involved in the aggregation of L. lactis subsp. lactis BGKP1 had a slightly smaller molecular mass than that of L. paracasei subsp. paracasei BGSJ2-8.

\section{Localization and cloning of genes linked to the aggregation phenomenon}

Plasmid profile analysis (of non-digested and digested plasmids with different restriction enzymes) of parental strain BGKP1 and the Agg- derivative BGKP1-20 showed differences in one plasmid designated as pKP1, indicating its potential role in the expression of the aggregation phenotype (Figure 3 ).

In order to facilitate cloning and expression of gene (s) responsible for the aggregation phenotype in homologous and heterologous hosts, new lactococcalE. coli shuttle cloning vectors pAZIL and pAZILcos, based on pACYC184 [28] and pIL253 [29] were constructed [see Additional File 1]. These vectors enabled cloning of large DNA fragments (entire pKP1 - 16.2 $\mathrm{kb})$, blue-white selection for the inserted fragments and high stability of the constructs. The plasmid library of pKP1 constructed in PAZIL enabled sequencing and subsequent in silico analysis of the obtained sequence.

\section{Sequence analyses of plasmid pKP1}

The complete sequence of plasmid pKP1 was found to consist of $16181 \mathrm{bp}$, with a $\mathrm{G}+\mathrm{C}$ content of $35.94 \%$. Within the 4380 bp long nucleotide sequence of pKP1 (region 15394-1-3593), a 99\% identity with the pSRQ900 plasmid of Lactococcus lactis (GenBank Accession No. AF001314) was determined. This sequence represented approximately one fourth of the pKP1 nucleotide sequence. This region encompassed the origin of replication, repB gene, repX replication associated gene and putative $h s d S$ gene (Figure 4). The rest of the nucleotide sequence (three quarters of pKP1) did not share identity with PSRQ900 and carried three genes, including two new genes (aggL and $m b p L$ ) and one known transposase gene, which implies its novelty. 


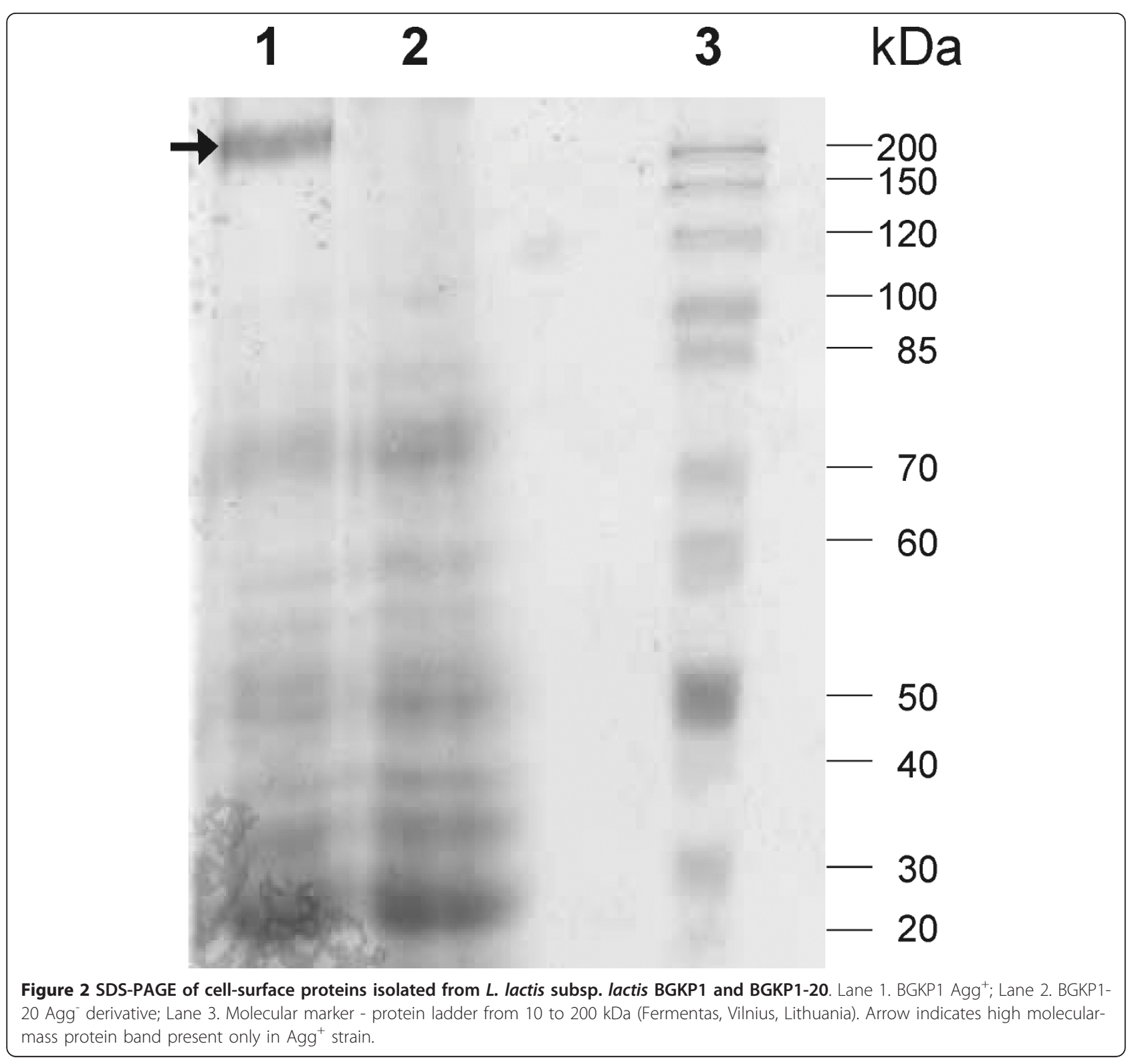

In addition, seven open reading frames (ORF) were revealed in pKP1 by application of the DNA Strider program (Table 1, Figure 4). It is interesting that all ORFs on the plasmid were in the same orientation except the gene encoding for transposase. Two potential ORFs, designated as aggL and $m b p L$, were additionally analysed. BLAST search revealed that aggL gene showed no similarity with any of the genes from the NCBI BLAST database, while AggL protein shared 51\% identity with a hypothetical protein from Oenococcus oeni AWRIB429 (Table 1). The nucleotide sequence of $m b p L$ shared $84 \%$ identity with ORF from Leuconostoc citreum KM20 plasmid pLCK 1 and 53\% amino acid identity with a protein from Enterococcus faecalis TX1322 (Table 1). Motif
Scan http://myhits.isb-sib.ch/cgi-bin/motif_scan and DAS Transmembrane Domain [30] programs were used to analyse their potential protein products. It was revealed that AggL included several motifs important for cell adhesion, such as a collagen-binding domain with a jelly-roll fold (C-terminus), CnaB-like domain (Cterminus) as well as serine and threonine-rich domains (N-terminus). MbpL contained a MucBP-like domain and YSIRK-signal. Both AggL and MbpL were predicted to have the Gram-positive cocci cell wall anchoring domain (LPXTG) and two transmembrane domains (by using strict cutoff). Additionally, both proteins had short amino acid repeat regions at the $\mathrm{N}$-terminus, serine and threonine rich regions for AggL and an alanine rich 


\section{$\begin{array}{llllllllll}1 & 2 & 3 & 4 & 5 & 6 & 7 & 8 & 9 & \mathrm{~kb}\end{array}$

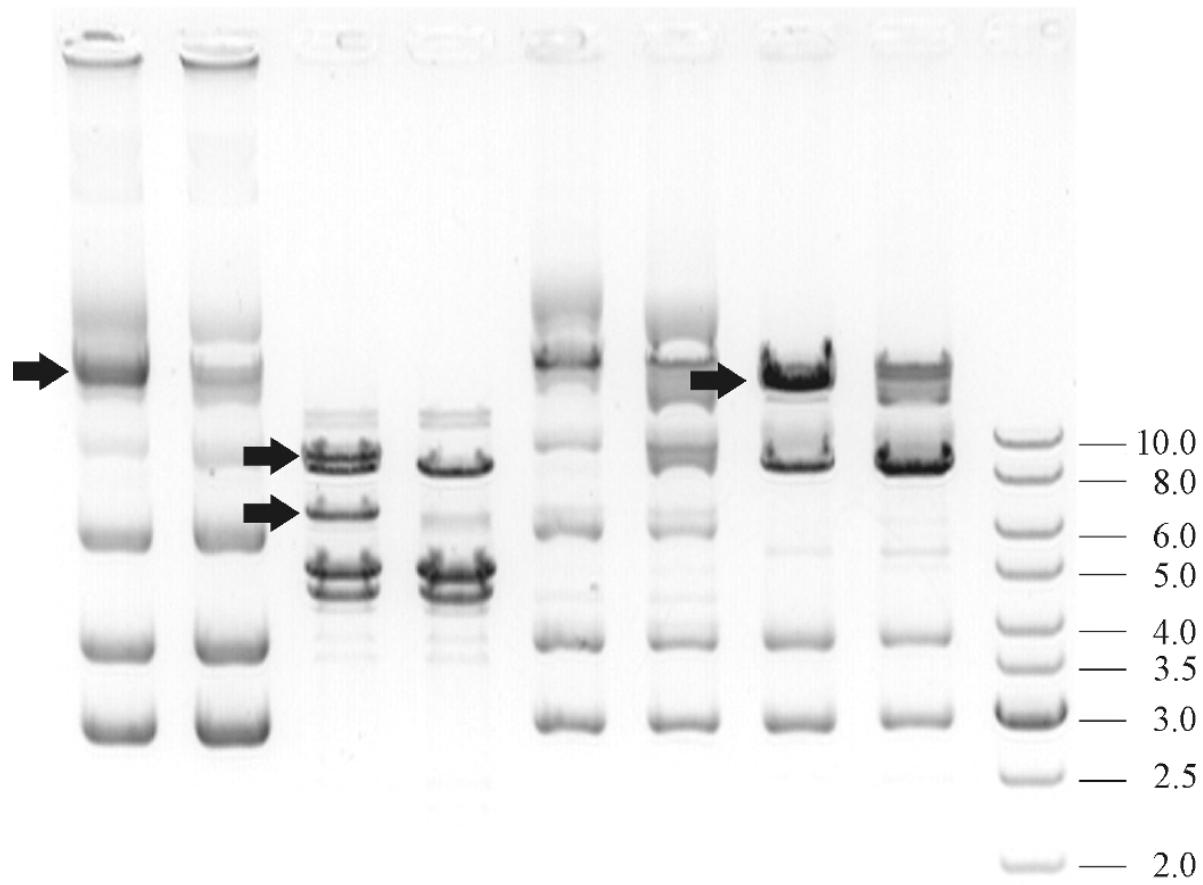

Figure 3 Plasmid profiles of L. lactis subsp. lactis BGKP1 Agg ${ }^{+}$(Lanes 1, 3, 5 and 7) and BGKP1-20 Agg derivative (Lanes 2, 4, 6 and 8) analysed on $1 \%$ agarose gel. Lanes 1 and 2, non-digested plasmids; Lanes 3 and 4, plasmids digested with EcoRl restriction enzyme; Lanes 5 and 6, plasmids digested with Pstl restriction enzyme; Lanes 7 and 8, plasmids digested with Sall restriction enzyme; Lane 9. Gene Ruler DNA size marker (Fermentas, Vilnius, Lithuania). Arrows indicate positions of plasmid bands/fragments present only in L. lactis subsp. lactis BGKP1 Agg ${ }^{+}$ strain.

region for MbpL. MbpL had five identical consecutive repeats at its $\mathrm{N}$-terminus, each encompassing 26 aa (AETASSSSSS AVKAETTSAS SSSAVK) starting at position 71 and ending at position 200, and two identical repeats at its C-terminus consisting of 36 aa (GDSYTTEQKA IPGYTFKAVQ GNPTGQFTSD AQTVTY), the first at position 750-785 and the second at 890-925. At its C-terminus, AggL protein encompassed four repeats of 70 aa (NTHQVAKTSV SGQKTWSDHD NQDGLRPDEI TVNLLADGKK VDSKTVTAKD GWKYEFNDLD KFKAGQEIKY) organised in two pairs with a space of 21 aa between repeats and 118 aa between pairs (repeat positions: I-1241-1310; II-13311400; III-1518-1587 and IV-1608-1677) [see Additional file 2].

Primary structural analysis of AggL revealed domain organization similar to LPXTG proteins of Gram-positive cocci. The LPXTG motif is a highly conserved part of the C-terminal sorting signal and it plays a role in the covalent linkage of many cell-wall-associated surface proteins to the nascent pentaglycine crossbridge in peptidoglycan [22]. For example, S. aureus is known to express 21 proteins with the LPXTG motif including two clumping factors ClfA and ClfB [20,31]. Another characteristic of AggL primary protein structure is modular architecture and a number of repeat regions that share high mutual identity (98-100\%). Previous studies on staphylococcal LPXTG proteins indicated modular architecture and B repeats as their specific characteristics. Such organization could have arisen during evolution through the acquisition of distinct domain-sized polypeptides of which some have expanded by duplication and homologous recombination [31]. Collagenbinding protein $\mathrm{B}$ domain ( $\mathrm{CnaB}$ domain) is the most abundant domain of AggL. Such a structure might mediate bacterial adherence to collagen. Repeated units have been suggested to serve as a 'stalk' that projects the region crucial for adherence to the bacterial surface, thus facilitating bacterial adherence to collagen. Additionally, the $\mathrm{N}$-terminal serine and threonine rich domains of AggL could play a role in aggregation, since it is known that such domains of CD46 protein promote 


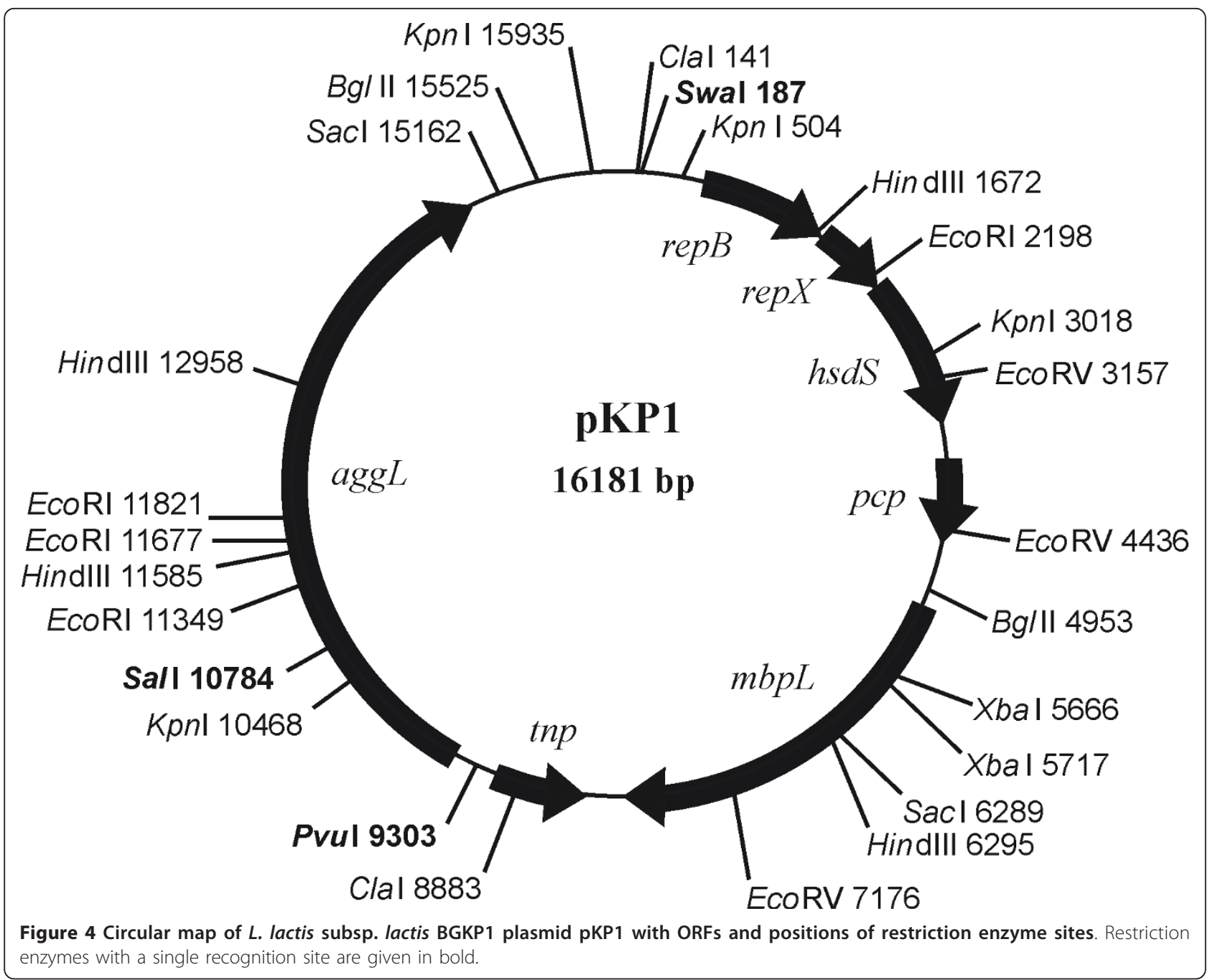

Table 1 General features of putative ORFs from pKP1 with best matches to sequences in the public database

\begin{tabular}{|c|c|c|c|c|c|c|}
\hline $\begin{array}{l}\text { Protein or } \\
\text { gene }\end{array}$ & Position & $\begin{array}{l}\text { Size } \\
\text { (nc/aa) }\end{array}$ & Proposed function & Source strain & $\begin{array}{c}\% \text { of identity } \\
\text { (nc/aa) }\end{array}$ & $\begin{array}{l}\text { GenBank accession } \\
\text { no. (nc/aa) }\end{array}$ \\
\hline RepB & $\begin{array}{l}600- \\
1760\end{array}$ & $\begin{array}{l}1161 / \\
386\end{array}$ & replication protein & Lactococcus lactis plasmid pSRQ900 & $99 / 99$ & $\begin{array}{l}\text { AF001314.1/ } \\
\text { NP_862549.1 }\end{array}$ \\
\hline RepX & $\begin{array}{l}1757- \\
2344\end{array}$ & $588 / 195$ & $\begin{array}{l}\text { replication associated } \\
\text { protein }\end{array}$ & Lactococcus lactis plasmid pSRQ900 & $100 / 100$ & $\begin{array}{l}\text { AF001314.2/ } \\
\text { NP_862550.1 }\end{array}$ \\
\hline HsdS & $\begin{array}{l}2320- \\
3510\end{array}$ & $\begin{array}{l}1191 / \\
396\end{array}$ & $\begin{array}{l}\text { Lldl type R/M, specificity } \\
\text { subunit (HsdS) }\end{array}$ & Lactococcus lactis plasmid pSRQ900 & $100 / 100$ & $\begin{array}{l}\text { AF001314.2/ } \\
\text { NP_862551.1 }\end{array}$ \\
\hline$p c p$ & $\begin{array}{l}3821- \\
4468\end{array}$ & $648 / 215$ & $\begin{array}{l}\text { pyrrolidone-carboxylate } \\
\text { peptidase }\end{array}$ & Lactococcus lactis plasmid pSK11P & $99 / 99$ & $\begin{array}{l}\text { DQ149245.1/ } \\
\text { ABA43397.1 }\end{array}$ \\
\hline$m b p L$ & $\begin{array}{l}5022- \\
8018\end{array}$ & $\begin{array}{l}2997 / \\
998\end{array}$ & $\begin{array}{l}\text { mucin-binding domain } \\
\text { protein }\end{array}$ & $\begin{array}{l}\text { Leuconostoc citreum KM20 plasmid pLCK1/ } \\
\text { Enterococcus faecalis TX1322 }\end{array}$ & $84 / 53$ & $\begin{array}{l}\text { DQ489740.1/ } \\
\text { ZP_04433966.1 }\end{array}$ \\
\hline Tnp & $\begin{array}{l}9170- \\
8484\end{array}$ & $687 / 228$ & IS1216 transposase & $\begin{array}{l}\text { Enterococcus faecalis strain } \\
\text { EF-01 plasmid pEF-01/Enterococcus faecalis }\end{array}$ & $99 / 99$ & $\begin{array}{l}\text { CP002208.2/ } \\
\text { YP003896017.1 }\end{array}$ \\
\hline aggl & $\begin{array}{l}9526- \\
14829\end{array}$ & $\begin{array}{l}5304 / \\
1767\end{array}$ & $\begin{array}{l}\text { lactococcal aggregation } \\
\text { factor }\end{array}$ & No similarity/Oenococcus oeni AWRIB429. & $-/ 51$ & -/ZР06554154.1 \\
\hline
\end{tabular}

nc - nucleotide

aa - amino acid 
efficient adherence of Neisseria gonorrhoeae to host cells [32]. Interestingly, the YSIRK domain, another characteristic of staphylococcal LPXTG proteins, was not found in AggL, although it was present within the signal peptide of MbpL. The requirement of a YSIRK motif for efficient secretion implies the existence of a specialized mode of substrate recognition by the secretion pathway of Gram-positive cocci. However, this mechanism is not essential for the surface protein to anchor to the cell wall envelope [33]. Considering the primary protein organization of $\mathrm{MbpL}$, its role in the cell could most likely be interaction with gastrointestinal epithelial cells. Interestingly, the search for lactococcal proteins similar to AggL and MbpL against the NCBI BLAST database revealed that AggL shared identity only within its $\mathrm{N}$ terminal region (encompassing transmembrane domain, serine and threonine rich domains, collagen binding domain and WD repeats). On the other hand, MbpL shared identity within its $\mathrm{C}$-terminal region (encompassing the MucBP-like domain including 36 aa repeats, the transmembrane domain and the $\mathrm{G}+$ anchoring domain).

\section{Homologous and heterologous expression of the aggL} gene

Cloning of different fragments of plasmid pKP1 into the pAZIL vector (Figure 5) and transfer of constructs into three lactococcal strains (homologous Agg- derivative BGKP1-20, and heterologous MG1363, BGMN1-596 and Enterococcus faecalis BGZLS10-27) revealed that the aggL gene is sufficient for the aggregation phenotype (Figure 1). Furthermore, aggregation of enterococcal cells carrying the aggL gene was observed, but the intensity of cell aggregation was lower than that obtained in lactococci (data not shown).
This conclusion was confirmed by transformation of the same lactococci with two types of constructs: pAZIL harboring pKP1 linearized in the aggL gene, that results in the inactivation of this gene (construct pAZIL-KPSl8) and by constructs carrying the DNA fragment of pKP1 containing solely the aggL gene (for example pAZIL-KPPvSc1) (Figure 5). It was noticed that cell aggregation phenotypes of MG1363 and BGKP1-20 transformants, carrying the aggL gene, were identical to those of the parental strain BGKP1. Transformants of BGMN1-596 showed the aggregation phenotype with slightly different cell aggregates, which were smaller than in BGKP1 (Figure 1).

The location of the gene involved in the aggregation of BGKP1 on plasmid pKP1 potentially enables transfer of this factor through the microbial population.

Experiments with heterologous expression of aggL and/ or $m b p L$ revealed the main role of AggL protein in the aggregation phenomena. According to the morphological characteristics of cell aggregates in heterologous strains, we can assume that even though AggL is crucial for aggregation, some additional protein(s) (like $\mathrm{MbpL}$ ) might have a modulatory effect on the aggregation phenotype. Additionally, preliminary ex vivo experiments with rat colon sections indicated that AggL is not involved in adhesion to the gastrointestinal epithelium (data not shown).

Further experiments will be focused on studies of AggL and MbpL interactions with human epithelial cells and their role in the adhesion and possible probiotic potential of BGKP1. Moreover, co-aggregation with various pathogenic bacteria will be also tested.

\section{Conclusions}

We have demonstrated that in lactococci, a novel aggregation-promoting factor AggL is encoded by the $\operatorname{aggL}$

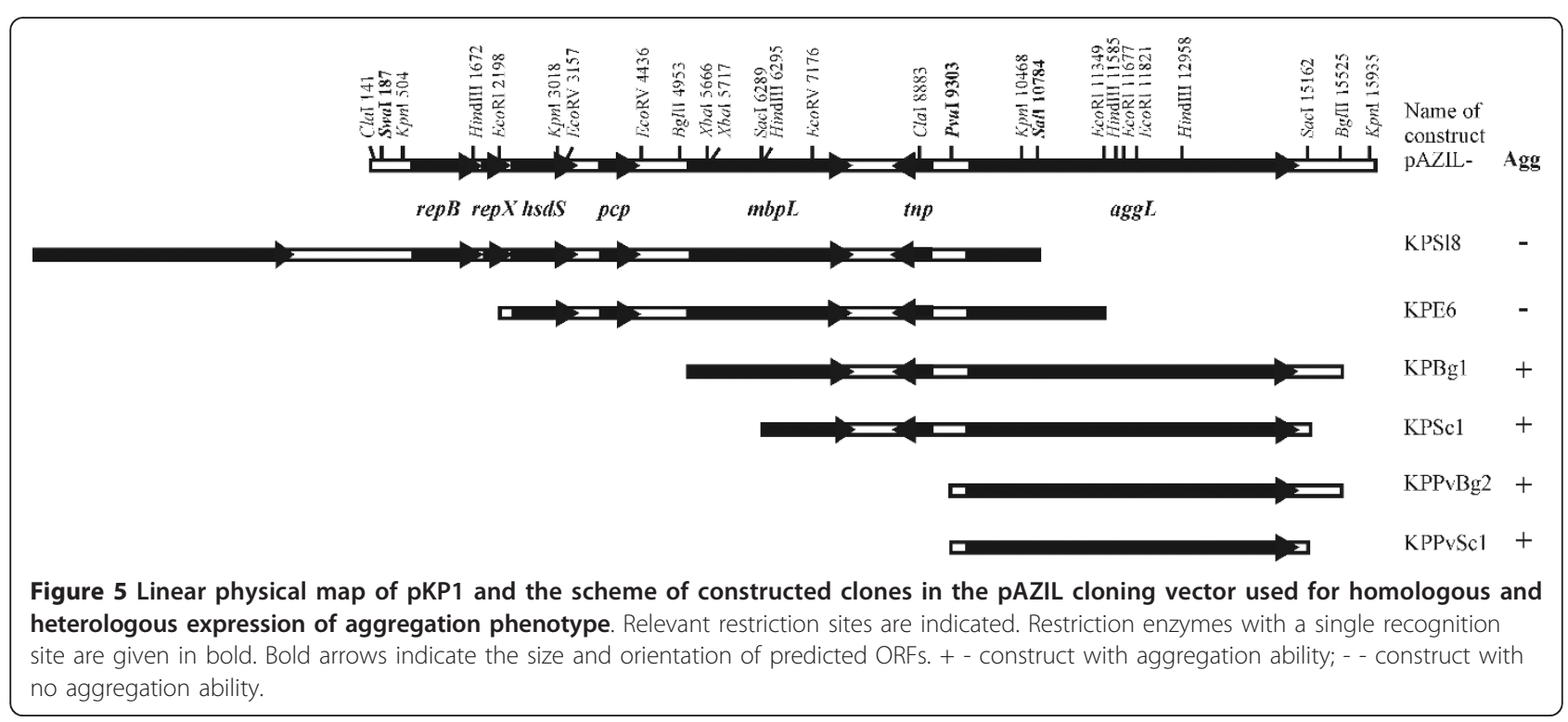


gene located on the $16.2 \mathrm{~kb}$ pKP1 plasmid. Moreover, functionality of $a g g L$ was confirmed by homologous and heterologous expression of different clones containing or lacking this gene in the newly constructed shuttlecloning vector, pAZIL.

\section{Methods}

Bacterial strains, media, growth conditions and transformations

Lactococcus lactis subsp. lactis BGKP1 ( $\left.\mathrm{Agg}^{+}\right)$was isolated from semi-hard homemade cheese using standard microbiological procedures. Preliminary strain classification was done according to its fermentation ability using API 50CHL (Api System SA; Bio-Merieux, MontelieuVercieu, France), temperature of growth $\left(30^{\circ} \mathrm{C}, 37^{\circ} \mathrm{C}\right.$, and $45^{\circ} \mathrm{C}$ ), growth in the presence of salt ( $4 \%$ and $\left.6.5 \%\right)$ and $\mathrm{pH}$ tolerance. Further taxonomic classification of BGKP1 involved repPCR with (GTG) 5 primer [34], and sequencing of amplified 16S rDNA [35]. A non-aggregating derivative BGKP1-20 (Agg-), L. lactis subsp. lactis BGMN1-596 (9), L. lactis subsp. cremoris MG1363 [36] and Enterococcus faecalis BGZLS10-27 [37] were used for homologous and heterologous expression of the aggregation phenotype. Lactococcal and enterococcal strains were grown at $30^{\circ} \mathrm{C}$ in M17 medium [38] supplemented with $0.5 \%$ glucose (GM17) and stored in the same medium containing $15 \%(\mathrm{w} / \mathrm{v})$ glycerol (Sigma Chemie $\mathrm{GmbH}$, Deisenhofen, Germany) at $-80^{\circ} \mathrm{C}$. L. lactis and E. faecalis electrocompetent cells were prepared and transformed as previously described [39] using an Eppendorf Electroporator (Eppendorf, Hamburg, Germany). E. coli strain DH5 $\alpha$ [40] was used for cloning experiments and plasmid propagation. $\mathrm{DH} 5 \alpha$ was grown at $37^{\circ} \mathrm{C}$ in LuriaBertani (LB) medium [41]. Agar plates were prepared by addition of agar $(1.5 \% \mathrm{w} / \mathrm{v})$ to the corresponding broth. E. coli competent cells were prepared using chemical treatment and subjected to heat shock transformation. Transformants were selected using the antibiotic erythromycin $\left(5 \mu \mathrm{g} \mathrm{ml}^{-1}\right.$ for lactococci and enterococci or $250 \mu \mathrm{g}$ $\mathrm{ml}^{-1}$ for $E$. coli). Bacteriocin and proteinase activity were determined as described previously [9].

\section{Growth kinetics}

Cultures of BGKP1 and BGKP1-20 were grown in $10 \mathrm{ml}$ of GM17 to a density of $10^{9}$ cells $\mathrm{ml}^{-1}$. Approximately $10^{6}$ cells of each strain were added to $10 \mathrm{ml}$ of GM17 and cultures were incubated at $30^{\circ} \mathrm{C}$. Aliquots from each culture were taken every hour and plated on solid GM17 medium to calculate generation time for each strain. Experiments were done in triplicate.

\section{Molecular techniques}

Molecular cloning techniques like end filling of DNA fragments with the Klenow fragment of DNA polymerase, dephosphorylation, ligation, PCR amplification and agarose gel DNA electrophoresis were carried out essentially as described previously [41]. The miniprep method [42] was used for isolation of large plasmids from lactococci. Plasmids from E. coli were isolated using the QIAprep Spin Miniprep kit according to the manufacturer's recommendations (QIAGEN, Hilden, Germany). The DNA fragments from agarose gels were purified using a QIAqick Gel extraction kit as described by the manufacturer (QIAGEN). Digestion with restriction enzymes was conducted according to the supplier's instructions (Fermentas, Vilnius, Lithuania).

\section{Determination of the effect of ions, $\mathrm{pH}$ and proteinase $\mathrm{K}$} on aggregation ability of $L$. lactis subsp. lactis BGKP1

The effect of different ions and $\mathrm{pH}$ values on the BGKP1 aggregation phenotype was tested using cells that were three times washed in bi-distilled water until the aggregation phenotype was lost. Cells were then resuspended in buffers of different $\mathrm{pH}$ and solutions of various ions. The following buffers were used: $\mathrm{KCl}(\mathrm{pH}$ 3.0), HCl-glycine ( $\mathrm{pH} 3.0$ ), Na-citrate ( $\mathrm{pH} 4.0$ to 6.0), Tris- $\mathrm{HCl}$ (pH 7.0 to 10.0) and Tris- $\mathrm{NaOH}(\mathrm{pH} 11.0$ to 12.0). The following ions were examined: $\mathrm{K}^{+}, \mathrm{Na}^{+}, \mathrm{Ca}^{++}$, $\mathrm{Mg}^{++}$and $\mathrm{Fe}^{+++}$in concentrations of $0.1,1$, and $10 \mathrm{mM}$. Proteinase $\mathrm{K}\left(1 \mu \mathrm{g} \mathrm{ml}^{-1}\right)$ treatment was done in TE (10 $\mathrm{mM}$ Tris, $1 \mathrm{mM}$ EDTA, pH8) buffer for $1 \mathrm{~h}$ at $37^{\circ} \mathrm{C}$. Determination of aggregation phenotype was based on absorption at $600 \mathrm{~nm}$.

\section{Biofilm formation}

The ability of BGKP1 and BGKP1-20 to form biofilms was tested as previously described by Christensen and coauthors [43]. Pseudomonas aeruginosa PAO1 and Escherichia coli $\mathrm{DH} 5 \alpha$ were used as the positive and negative control strains respectively. The experiments were done in triplicate.

\section{Analysis of cell surface proteins of L. lactis subsp. lactis BGKP1 and its non-aggregating derivative}

Cells from overnight culture $(250 \mathrm{ml})$ of strain BGKP1 and its Agg- derivative BGKP1-20 were harvested by centrifugation and washed in $50 \mathrm{ml}$ bi-distilled water. Proteins from the wash were precipitated with ammonium sulphate (25\% saturation). Precipitated proteins were resuspended in $10 \mathrm{mM}$ Tris- $\mathrm{HCl}, \mathrm{pH} 8.5$, and applied on SDS-PAGE (10\%). The obtained bands were visualized by Coomassie blue staining.

\section{Construction of shuttle-cloning vectors}

The pAZIL shuttle-cloning vector and pAZILcos cosmid vector were constructed in order to perform the molecular analysis of BGKP1 plasmid pKP1 [see Additional File 1]. The tetracycline resistance gene of pACYC184 
was replaced with the $l a c Z$ gene from the replicative form of M13 mp18 phage using ClaI/NarI and HincII/ AvaII restriction enzymes, resulting in cloning vector pAZ1. In the next step, the chloramphenicol resistance gene from pAZ1 was removed using $S c a \mathrm{I}$ and $\mathrm{XmnI}$ restriction enzymes and the vector was fused with lactococcal cloning vector pIL253, previously digested with EcoRI-XbaI restriction enzymes and blunted with Klenow enzyme, resulting in shuttle cloning vector pAZIL.

To obtain a cosmid vector for the construction of cosmid libraries of lactococcal genomes, the cos site was introduced into the unique SacII (7697) restriction site of the pAZIL vector. The DNA fragment containing the cos site was obtained by PCR amplification with primers cosF-CATGTTTGACCGCGGATCATCG and cosRCTAGACACCGCGGAAGCTAGC (SacII restriction sites are underlined). Afterwards, the PCR amplicon was digested with SacII and ligated with SacII-digested pAZIL resulting in the pAZILcos cosmid vector.

\section{Construction of various plasmid pKP1 derivatives}

Strain BGKP1 harbors at least three plasmids. Total plasmids isolated from strain BGKP1 were digested with different restriction enzymes (SalI, EcoRI, BglII, SacI, $P v u \mathrm{I}$ and $B g l \mathrm{II}, S a c \mathrm{I}$ and $P v u \mathrm{I})$. The resulting fragments were cloned into pAZIL vector digested with the same restriction enzymes (except for BglII, which was cloned into BamHI) and selected in E. coli DH5 $\alpha$ by the blue/white color method on LB plates containing erythromycin (250 $\left.\mu \mathrm{g} \mathrm{ml}^{-1}\right)$, IPTG $(0.1 \mathrm{mM})$ and X-Gal $\left(40 \mu \mathrm{g} \mathrm{ml}^{-1}\right)$. The obtained constructs carrying fragments of the largest plasmid pKP1 were designed as pAZIL-KPSl8 (16181 bp pKP1 plasmid linearized in SalI at position 10784 resulting in a disrupted aggL gene), pAZIL-KPE6 (9151 bp EcoRI fragment of pKP1, position 2198-11349), pAZILKPBg1 (10572 bp BglII fragment of pKP1, position 495315525), pAZIL-KPSc1 (8873 bp SacI fragment of pKP1, 6289-15162), pAZIL-KPPvBg2 (6322 bp PvuI-BglII fragment of pKP1, position 9303-15525), and pAZILKPPvSc1 (5859 bp PvuI-SacI fragment of pKP1, 930315162). Restriction enzyme digestion and sequencing of the constructs were performed to show that the anticipated final plasmid constructs had been obtained. The constructs were isolated from E. coli and then transferred to L. lactis subsp. lactis BGKP1-20 ( $\left.\mathrm{Agg}^{-}\right)$, L. lactis subsp. lactis BGMN1-596 and L. lactis subsp. cremoris MG1363 by electroporation. The obtained $\mathrm{Em}^{\mathrm{r}}$ transformants were tested for expression of the aggregation phenotype.

\section{DNA sequencing and analysis}

For DNA sequencing, pAZIL-KPSl8 and the other constructs aforementioned were isolated from E. coli using a QIAprep Spin Miniprep Kit (QIAGEN) as recommended by the manufacturer. Plasmids were sequenced by primer-walking of both strands in Macrogen's sequencing service (Seoul, Korea). Sequence annotation and the database search for similar sequences were performed using BLAST site programs at the National Center for Biotechnology Information [44]. The DNA Strider program was used for open reading frame (ORF) prediction.

\section{Nucleotide sequence accession number}

The nucleotide sequences of the partial 16S rDNA sequence of $L$. lactis subsp. lactis BGKP1, plasmids pAZILcos and pKP1 were submitted to the EMBL GenBank under accession numbers FR873574, FR872379 and FR872378, respectively.

\section{Additional material}

Additional file 1: Construction strategy and the restriction enzyme maps of the lactococci/E. coli shuttle-cloning and cosmid vectors, pAZIL and pAZILcos. PAZIL shuttle-cloning vector was constructed in the following order: tetracycline resistance gene of PACYC184 was replaced with the lacZ gene from the replicative form of M13 mp18 phage using Clal/Narl and Hincll/Avall restriction enzymes, resulting in cloning vector pAZ1. Subsequently chloramphenicol resistance gene from pAZ1 was removed using Scal and Xmnl restriction enzymes and the vector was fused with lactococcal cloning vector pIL253, resulting in shuttle cloning vector PAZIL. Cosmid vector PAZILcos was obtained by introduction of cos site into the unique Sacll (7697) restriction site of the pAZIL vector. Only relevant restriction enzymes are shown. Restriction enzymes with a single recognition site are given in bold.

Additional file 2: Schematic presentation of AggL and MbpL proteins. Boxes indicate domains of proteins and arrows indicate repeats.

\section{Acknowledgements and funding}

The authors are grateful to Dr Anna Nikolic, a native English Scientific Counsellor for editing the language. This work was supported by the Ministry of Education and Science, Republic of Serbia (Grant No. 173019), and by the International Centre of Genetic Engineering and Biotechnology, Italy (Grant CRP-YUG10-01).

\section{Authors' contributions}

MK was responsible for the conception and design of the study, and was involved in construction of shuttle-cloning vectors, pKP1 plasmid cloning and sequencing as well as in writing the draft and final version of the manuscript. BJ performed the experiments to analyse cell surface proteins and the effects of ions, $\mathrm{pH}$ and proteinase $\mathrm{K}$ on aggregation ability of the analysed strains, and was involved in sequencing and in silico analysis of PKP1 plasmid. IS participated in construction of plasmid pKP1 derivatives. JB was involved in construction of PAZ1, pAZIL and PAZILcos vectors and interpretation of data. JL participated in homologous and heterologous expression of aggregation phenotype. KV carried out plasmid profile analysis and standardization of transformation protocols. LT critically revised the manuscript and gave final approval of the version to be published. All authors read and approved the final manuscript.

Received: 9 September 2011 Accepted: 19 December 2011 Published: 19 December 2011

\section{References}

1. Gasson MJ, Swindell S, Maeda S, Dodd HM: Molecular rearrangement of lactose plasmid DNA associated with high-frequency transfer and cell aggregation in Lactococcus lactis 712. Mol Microbiol 1992, 6:3213-3223. 
2. Gajic O: Relationships between MDR proteins, bacteriocin production and proteolysis in Lactococcus lactis. PhD thesis University of Groningen; 2003.

3. Anderson DG, McKay LL: Genetic and physical characterization of recombinant plasmids associated with cell aggregation and high frequency conjugal transfer in Streptococcus lactis ML3. J Bacteriol 1984 158:954-962.

4. Gasson MJ, Davies FL: High-frequency conjugation associated with Streptococcus lactis donor cell aggregation. J Bacteriol 1980, 143:1260-1264

5. Walsh PM, McKay LL: Recombinant plasmid associated with cell aggregation and high-frequency conjugation of Streptococcus lactis ML3. J Bacteriol 1981, 146:937-944.

6. Bringel F, van Alstine GL, Scot JR: Transfer of Tn916 between Lactococcus lactis subsp. lactis strains is nontranspositional: evidence for a chromosomal fertility function in strain MG1363. J Bacteriol 1992, 174:584-5847.

7. Stentz R, Jury K, Eaton T, Parker M, Narbad A, Gasson M, Shearman C: Controlled expression of CluA in Lactococcus lactis and its role in conjugation. Microbiology 2004, 150:2503-2512.

8. Stentz R, Gasson M, Shearman C: The Tra domain of the lactococcal CluA surface protein is a unique domain that contributes to sex factor DNA transfer. J Bacteriol 2006, 188:2106-2114

9. Kojic M, Strahinic I, Fira D, Jovcic B, Topisirovic L: Plasmid content and bacteriocin production by five strains of Lactococcus lactis isolated from semi-hard cheese. Can J Microbiol 2006, 52:1110-1120.

10. Fischetti VA, Pancholi V, Schneewind O: Conservation of a hexapeptide sequence in the anchor region of surface proteins from Gram-positive cocci. Mol Microbiol 1990, 4:1603-1605.

11. Navarre WW, Schneewind O: Surface proteins of Gram-positive bacteria and mechanisms of their targeting to the cell wall envelope. Microbiol Mol Biol Rev 1999, 63:174-229.

12. Jenkinson HF: Cell surface protein receptors in oral streptococci. FEMS Microbiol Lett 1994, 121:133-140.

13. Jenkinson HF, Demuth DR: Structure, function and immunogenicity of streptococcal antigen I/II polypeptides. Mol Microbiol 1997, 23:183-190.

14. Kolenbrander PE, London J: Adhere today, here tomorrow: oral bacteria adherence. J Bacteriol 1993, 175:3247-3252.

15. Jett BD, Atkuri RV, Gilmore MS: Enterococcus faecalis localization in experimental endophtalmitis: role of plasmid-encoded aggregation substance. Infect Immun 1998, 66:843-848.

16. Kreft $B$, Marre $R$, Schramm U, Wirth R: Aggregation substance of Enterococcus faecalis mediates adhesion to cultured renal tubular cells. Infect Immun 1992, 60:25-30.

17. Rakita RM, Vanek NN, Jacques-Palaz K, Mee M, Mariscalco MM, Dunny GM, Snuggs M, Van Winkle WB, Simon SI: Enterococcus faecalis bearing aggregation substance is resistant to killing by human neutrophiles despite phagocytosis and neutrophile activation. Infect Immun 1999, 67:6067-6075.

18. Schlievert PM, Gahr PJ, Assimacopoulos AP, Dinges MM, Stoehr JA, Harmala JW, Hirt H, Dunny GM: Aggregation and binding substances enhance pathogenicity in rabbit models of Enterococcus faecalis endocarditis. Infect Immun 1998, 66:218-223.

19. Süssmuth SD, Muscholl-Silberhorn A, Wirth $R$, Susa M, Marre R, Rozdzinski E: Aggregation substance promotes adherence, phagocytosis and intracellular survival of Enterococcus faecalis within human macrophages and suppresses respiratory burst. Infect Immun 2000, 68:4900-4906.

20. Foster TJ, Höök M: Surface protein adhesins of Staphylococcus aureus. Trends Microbiol 1998, 6:484-488.

21. Galli D, Friesenegger A, Wirth R: Transcriptional control of sexpheromone-inducible genes on plasmid PAD1 of Enterococcus faecalis and sequence analysis of a third structural gene for (pPD1-encoded) aggregation substance. Mol Microbiol 1992, 6:1297-1308.

22. Galli D, Lottspeich F, Wirth R: Sequence analysis of Enterococcus faecalis aggregation substance encoded by the sex pheromone plasmid pAD1. Mol Microbiol 1990, 4:895-904.

23. Kao SM, Olmsted SB, Viksnins AS, Gallo JC, Dunny GM: Molecular and genetic analysis of a region of plasmid pCF10 containing positive control genes and structural genes encoding surface proteins involved in pheromone-inducible conjugation in Enterococcus faecalis. J Bacteriol 1991, 173:7650-7664.
24. Hirt H, Erlandsen SL, Dunny GM: Heterologous inducible expression of Enterococcus faecalis pCF10 aggregation substance Asc10 in Lactococcus lactis and Streptococcus gordonii contributes to cell hydrophobicity and adhesion to fibrin. J Bacteriol 2000, 182:2299-2306.

25. Wells CL, Moore EA, Hoag JA, Hirt H, Dunny GM, Erlandsen SL: Inducible expression of Enterococcus faecalis aggregation substance surface protein facilitates bacterial internalization by cultured enterocytes. Infect Immun 2000, 68:7190-7194.

26. Lozo J, Jovcic B, Kojic M, Dalgalarrondo M, Chobert JM, Haertlé T, Topisirovic L: Molecular characterization of a novel bacteriocin and an unusually large aggregation factor of Lactobacillus paracasei subsp. paracasei BGSJ2-8, a natural isolate from homemade cheese. Curr Microbiol 2007, 55:266-271.

27. Huber B, Riedel K, Köthe M, Givskov M, Molin S, Eberl L: Genetic analysis of functions involved in the late stages of biofilm development in Burkholderia cepacia H111. Mol Microbiol 2002, 46:411-426.

28. Mok YK, Clark DR, Kam KM, Shaw PC: BsiY I, a novel thermophilic restriction endonuclease that recognizes $5^{\prime}$ CCNNNNNNNGG $3^{\prime}$ and the discovery of a wrongly sequenced site in pACYC177. Nucleic Acids Res 1991, 19:2321-2323.

29. Simon D, Chopin A: Construction of a vector plasmid family and its use for molecular cloning in Streptococcus lactis. Biochimie 1988, 70:559-566.

30. Cserzo M, Wallin E, Simon I, von Heijne G, Elofsson A: Prediction of transmembrane alpha-helices in procariotic membrane proteins: the Dense Alignment Surface method. Prot Eng 1997, 10:673-676.

31. Roche FM, Massey R, Peacock SJ, Day NP, Visai L, Speziale P, Lam A, Pallen M, Foster TJ: Characterization of novel LPXTG-containing proteins of Staphylococcus aureus identified from genome sequences. Microbiology 2003, 149:643-654

32. Källström H, Blackmer Gill D, Albiger B, Liszewski MK, Atkinson JP, Jonsson AB: Attachment of Neisseria gonorrhoeae to the cellular pilus receptor CD46: identification of domains important for bacterial adherence. Cell Microbiol 2001, 430:133-143.

33. Bae T, Schnewind O: The YSIRK-G/S motif of staphylococcal protein A and its role in efficiency of signal peptide processing. J Bacteriol 2003 185:2910-2919.

34. Versalovic J, Schneider M, de Bruijn F, Lupski JM: Genomic fingerprinting of bacteria using repetitive sequence based polymerase chain reaction. Meth Mol Cell Biol 1994, 5:25-40.

35. Jovcic B, Begovic J, Lozo J, Topisirovic L, Kojic M: Dynamics of sodium dodecyl sulfate utilization and antibiotic susceptibility of strain Pseudomonas sp. ATCC19151. Arch Biol Sci 2009, 61:159-164.

36. Gasson MJ: Plasmid complements of Streptococcus lactis NCDO 712 and other lactic streptococci after protoplast-induced curing. J Bacteriol 1983, 154:1-9.

37. Valenzuela AS, ben Omar N, Abriouel H, López RL, Veljovic K, Caňamero MM, Kojic M, Topisirovic L, Gálvez A: Virulence factors, antibiotic resistance, and bacteriocins in enterococci from artisan foods of animal origin. Food Control 2009, 20:381-385.

38. Terzaghi BE, Sandine WE: Improved medium for lactic streptococci. Curr Microbiol 1975, 7:245-250.

39. Holo H, Nes IF: Transformation of Lactococcus by electroporation. Meth Mol Biol 1995, 47:195-199.

40. Hanahan D: Studies of transformation of Escherichia coli with plasmids. $J$ Mol Biol 1983, 166:557-580.

41. Sambrook J, Fritsch EF, Maniatis T: Molecular cloning: a laboratory manual. 2 edition. Cold Spring Harbor Laboratory: New York; 1989.

42. O'Sullivan DJ, Klaenhammer TR: Rapid mini-prep isolation of high-quality plasmid DNA from Lactococcus and Lactobacillus ssp. Appl Environ Microbiol 1993, 59:2730-2733.

43. Christensen GD, Simpson WA, Younger JJ, Baddour LM, Barrett FF, Melton DM, Beachey EH: Adherence of coagulase-negative staphylococci to plastic tissue culture plates: a quantitative model for the adherence of staphylococci to medical devices. J Clin Microbiol 1985, 22:996-1006.

44. Altschul SF, Madden TL, Schäffer AA, Zhang J, Zhang Z, Miller W, Lipman DJ: Gapped BLAST and PSI-BLAST: a new generation of protein database search programs. NuC Acids Res 1997, 25:3389-3402.

doi:10.1186/1471-2180-11-265

Cite this article as: Kojic et al:: Cloning and expression of a novel lactococcal aggregation factor from Lactococcus lactis subsp. lactis BGKP1. BMC Microbiology 2011 11:265. 